\title{
ANALISIS PERUBAHAN SIFAT MEKANIK AL 6063 SETELAH DILAKUKAN HEAT TREATMENT PADA TEMPERATUR TETAP DENGAN WAKTU TAHAN YANG BERVARIASI
}

\author{
Media Nofri ${ }^{1}$ \\ Prodi Teknik Mesin - Universitas Tama Jagakarsa 12 \\ email $^{1}$ : medi.bagindo@gmail.com
}

\begin{abstract}
Aluminium is a material commonly used in human activity. On operating condition, people expect that aluminium has mechanical properties such as hardness. The mechanical properties can be improved by doing some treatment processes, such as by heat treatment. Al alloys 6063 has a smaller strength than other alloys, but very lithe. Al alloys 6063 also has very good ability to forging, and can be strengthened by heat treatment after processing. AI alloys 6063 contains chemical compotition 98.7\% Al, $0.530 \%$ Si and $0.532 \% \mathrm{Mg}$. AI alloys 6063 common used for frame construction, engine piston, cylinder head combustion engine, bicycle parts, etc, because alloys have excellent corrosion resistance properties than the other heated aluminium. In this research, Al 6063 will be heated on $530^{\circ} \mathrm{C}$ with variation holding time from 30 minutes to 60 minutes and then cooled by air. Next, observing microstructure. Finally, from the research results found Al dendrite structure and spread particle of $\mathrm{Si}$ and the formation of particle enlargment. Heat treatment of Al 6063 doesn't have big impact, heating process should be done with variation holding time over 60 minutes. Longer heating process will give higher hardness value or better.
\end{abstract}

Keywords: Aluminium 6063, Chemical composition, Heat treatment, Metallografi, Hardness.

\section{PENDAHULUAN}

Paduan Aluminium alloy tipe 6063 telah digunakan secara luas terutama pada industri manufaktur, seperti bagian - bagian pesawat, industri baut dan mur serta industri otomotif lainnya. Hal ini dikarenakan paduan ini memiliki keunggulan pada perbandingan kekuatan yang dihasilkan dengan berat struktur yang lebih tinggi dari pada baja, ketahanan lelah yang baik, keuletan serta sifat mampu bentuk yang tinggi. Selain sifat mekanik tersebut, sifat yang amat disukai pada paduan ini adalah sifat mampu dikuatkan

Tujuan penelitian untuk mengetahui perubahan sifat mekanik dan struktur mikro dengan cara menganalisa perubahan material kekerasan dari hasil proses yang di lakukan pada Aluminium alloy. Logam paduan akan mengalami perubahan sifat dan struktur mikro akibat proses pemanasan dengan media pedingin udara.

Adapun material yang akan diuji adalah aluminium tipe 6063 dimana material tersebut adalah bahan dasar dari piston sepeda motor 4 tak, hal ini dikarena pada piston tersebut sering mengalami kerusakan berupa goresan yang terdapat pada dinding piston, hal ini mungkin disebabkan kurangnya tingkat kekerasan pada pistong yang mengakibatkan pembakaran tidak sempurna. Berdasarkan hal tersebut maka akan dilakukan penelitian pada material Aluminium alloy tipe 6063 yang sudah di heat treatment untuk meningkatkan kekerasan sebagai bahan dasar piston.

Pembatasan masalah pada penelitian ini sebagai berikut:

1. Bahan yang digunakan sebagai penelitian yaitu Aluminium tipe 6063, terbagi menjadi 5 sampel, 1 sampel tanpa perlakuan panas dan 4 sample mendapatkan perlakuan panas dengan variasi waktu pemanasan yang berbeda - beda.

2. Pemanasan heat treatment dengan temperatur tetap $530^{\circ} \mathrm{C}$ dan waktu tahan (holding time) 30, 40,50, dan 60 menit yang kemudian di dinginkan dengan udara. 
3. Dilakukan uji kekerasan, struktur mikro, dan komposisi kimia untuk seluruh sample aluminium 6063.

Adapun manfaat yang akan didapat adalah :

1 Dapat diketahui perubahan sifat mekanik Al 6063 bila dilakukan heat treatment dengan temperature tetap dan waktu tahan yang bervariasi.

2 Selain itu juga dapat diketahui tingkat perubahan nilai kekerasan pada paduan aluminium tipe 6063 setelah mendapatkan perlakuan panas dengan temperatur tetap $530^{\circ} \mathrm{C}$ dengan variasi waktu mulai dari 30 menit sampai 60 menit.

3 Mengetahui perubahan stuktur mikro bahan paduan Aluminium tipe 6063 setelah mendapatkan pendinginan dengan media udara.

\section{TINJAUAN PUSTAKA \\ Aluminium}

Aluminium merupakan salah satu logam non ferro yang paling banyak di pakai pada konstruksi, penggunaanya sangat meluas, mulai dari industri otomotif sampai kesehatan, dan logam ini sangat berperan dalam perkembangan didunia penerbangan. Sifat-sifat penting yang menyebabkan Aluminium banyak dipakai adalah ringan, tahan korosi, penghantar listrik dan panas yang baik. Berat jenisnya hanya $2,7 \mathrm{~g} / \mathrm{cm}^{3}$ (kira kira sepertiga berat jenis baja) karenanya Aluminium banyak dipakai pada bagian - bagian pesawat terbang, kendaraan bermotor dan alat transpostasi lainnya. Alat transportasi harus dibuat seringan mungkin sehingga akan dapat mengangkut beban lebih banyak.

\section{Aluminium Paduan (Aluminium Alloy)}

Aluminium Alloy adalah bahan campuran yang mempunyai sifat - sifat logam, terdiri dari dua atau lebih unsur - unsur, dan sebagai unsur utama campuran adalah logam. Sebagai tambahan terhadap kekuatan mekaniknya yang sangat meningkat dengan penambahan $\mathrm{Cu}, \mathrm{Mg}, \mathrm{Si}, \mathrm{Mn}, \mathrm{Zn}, \mathrm{Ni}$, dan sebagainya, secara satu persatu atau bersama-sama.

\section{Klasifikasi Aluminium}

Alumunium alloy dikelompokkan dalam berbagai standard oleh berbagai Negara di dunia. Namun, pengklasifikasian yang paling terkenal dan sempurna adalah standard Alumunium Association (AA) di Amerika yang didasarkan pada standard sebelumnya dari Alumunium Company of America (ALCOA). Dalam penelitian ini kelompok Alumunium alloy yang dipakai adalah Alumunium Magnesium Silikon Alloy (seri 6xxx)

\section{Paduan Aluminium Mg2Si (Al 6063)}

Paduan Al 6063 termasuk dalam kelompok paduan $\mathrm{AlMgSi}$, dan seri 6xxx merupakan kelompok paduan yang dapat dilakukan proses heat treatment. Kelompok paduan $\mathrm{AlMgSi}$ dapat dikelompokkan lagi berdasarkan kandungan Magnesium dan Silikon serta sifat - sifat fisik maupun sifat mekanis yang dimilikinya. Kelompok paduan $\mathrm{AlMgSi}$ antara lain Al 6053, Al 6061, Al 6063, Al 6065 dsb.

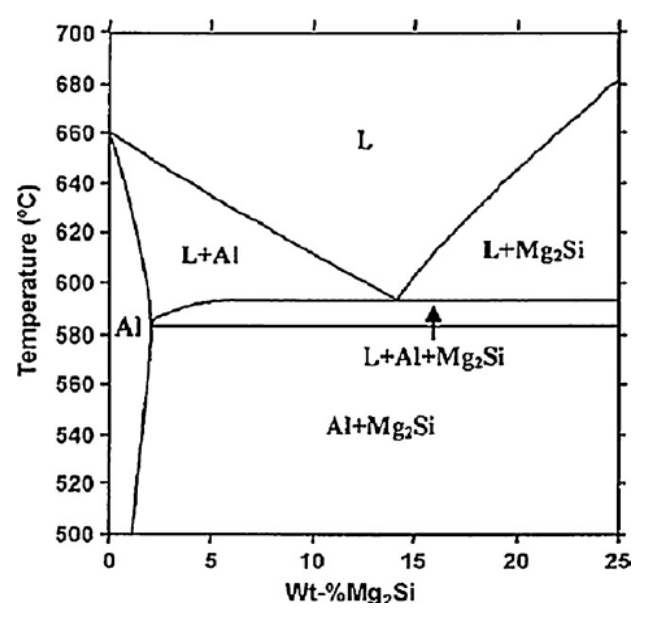

Gambar 1. Diagram Fasa Al-Mg2Si

Dalam seri ini termasuk juga Al 6063 yang merupakan paduan Aluminium bentukan, dimana Magnesium dan Silikon biasanya muncul dalam perbandingan tertentu untuk membentuk magnesium silika. Paduan Al 6063 memiliki sifat yang sangat baik ketahanan korosinya dan dapat ditingkatkan sifat mekanik dan sifat fisiknya dengan perlakuan panas. Mampu bentuknya sangat baik sehingga bahan Al 6063 ini banyak digunakan untuk keperluan arsitektur yaitu untuk pembuatan profil dengan cara ekstrusi dan juga untuk keperluan otomotif seperti untuk pembuatan badan, rangka dan juga rantai kendaraan bermotor.

Dari diagram fasa tersebut dapat ditunjukan beberapa fasa yang dapat terjadi tergantung pada komposisi $\mathrm{Mg}$ dan $\mathrm{Si}$, serta temperatur tertentu. Berdasarkan diagram fasa tersebut, komposisi paduan Al 6063 bisa membentuk fasa Mg2Si. Perbandingan yang tepat untuk pembentukan endapan atau fasa $\mathrm{Mg} 2 \mathrm{Si}$ adalah $\mathrm{Mg}$ : $\mathrm{Si}=1,73$. Tetapi hal ini tidak dapat dicapai dengan operasi biasa sehingga paduan akan mengandung $\mathrm{Mg}$ maupun Si yang berlebih. Kelebihan Magnesium $(\mathrm{Mg})$ mengakibatkan paduan lebih tahan terhadap korosi namun kekuatan dan mampu bentuknya rendah. Sedangkan kelebihan Silikon (Si) mengakibatkan paduan berkekuatan tinggi tanpa kehilangan mampu bentuk dan mampu las, tetapi cenderung terjadi korosi intergranular.

Selain itu untuk memperlihatkan secara lebih jelas kelarutan $\mathrm{Mg} 2 \mathrm{Si}$ dalam matrik Aluminium, dapat ditunjukkan dengan diagram fasa $\mathrm{Al}-\mathrm{Mg} 2 \mathrm{Si}$ seperti pada gambar 1. Dari diagram fasa tersebut terlihat bahwa kelarutan $\mathrm{Mg} 2 \mathrm{Si}$ dalam Aluminium 
akan menurun, dengan menurunnya temperatur yang merupakan persyaratan utama proses perlakuan panas pengerasan pengendapan (precipitation hardening).

Kelarutan maksimum dari Mg2Si pada fasa $\alpha$

Aluminium adalah $1,85 \%$ pada temperatur

$595{ }^{\circ} \mathrm{C}$, kemudian kelarutan tersebut menurun, dengan menurunnya temperatur pada temperatur dibawah $200{ }^{\circ} \mathrm{C}$ kelarutan $\mathrm{Mg} 2 \mathrm{Si}$ ini hampir mendekati $0 \%$. Pada daerah dengan komposis $0-$ $1,85 \% \mathrm{Mg} 2 \mathrm{Si}$ dan temperatur $200{ }^{\circ} \mathrm{C}$ sampai temperatur $595{ }^{\circ} \mathrm{C}$ merupakan daerah untuk melakukan proses perlakuan panas pengerasan pengendapan diantara garis solvus dan liquidus seperti yang ditunjukan pada gambar 1 .

\section{Perlakuan Panas (Heat Treatment)}

Perlakuan panas atau heat treatment merupakan suatu proses pemanasan sampai temperature tertentu, mempertahankan suhu untuk waktu tertentu dan pendinginan yang terkontrol, dengan tujuan mengubah sifat mekanis dari bahan sesuai dengan yang dinginkan. Adapun tujuan dari masing - masing proses yaitu :

\section{Pemanasan}

Adalah suatu proses pemanasan sampai temperatur tertentu dan dalam periode waktu. Tujuannya untuk memberikan kesempatan agar terjadinya perubahan struktur dari atom-atom dapat menyeluruh.

\section{Waktu tahan}

Proses penahanan pemanasan pada temperatur tertentu, bertujuan untuk memberikan kesempatan agar terbentuk struktur yang teratur dan seragam sebelum proses pendinginan.

\section{Pendinginan}

Proses pendinginan dengan kecepatan tertentu, bertujuan untuk mendapatkan struktur dan sifat fisik maupun sifat mekanis yang diinginkan.

Dalam perkembangan terakhir heat treatment dapat dikombinasikan dengan reaksi kimia sehingga disebut thermo kimia dan juga digabung dengan perlakuan mekanis sehingga disebut perlakuan thermo mekanis.

Pada proses perlakuan panas sifat-sifat logam dapat berubah karena terjadinya beberapa perubahaan mikro struktur, perubahaan fasa, terbentuknya presipitat, perubahaan ukuran butiran, perubahaan kandungan unsur kimia tertentu, terbentuknya karbida, dan lain-lain. Sedangkan sifat mekanis yang dapat berubah antara lain kuat tarik, keliatan, kekerasan, ketahanan aus, ketahanan fatigue, kemampuan bentuk, ketangguhan, dan lainlain. Karena banyaknya sifat mekanis yang memungkinkan dapat diubah, maka suatu proses perlakuan panas sudah merupakan suatu bagian dari rangkaian proses produksi dari industri komponen yang terbuat dari logam, khususnya besi baja

\section{Proses Perlakuan Panas (Heat Treatment)}

Secara umum macam macam heat treatment adalah Anneling, Normalising, Hardening dan Tempering

\section{Annealing}

Adalah proses heat treatment yang dapat digunakan untuk, mengurangi kekerasan, menghilangkan tegangan sisa, memperbaiki kekuatan, memperbaiki ductility dan menghaluskan ukuran butiran.

\section{Normalizing}

Merupakan proses perlakuan panas untuk menghasilkan struktur butiran yang halus, Secara teknis prosesnya hampir sama dengan Annealing, yaitu dilakukan dengan memanaskan logam sampai di atas temperature kritis $660{ }^{\circ} \mathrm{C}$ Kemudian dilanjutkan dengan pendinginan pada udara.

\section{Hardening}

Hardening adalah pengerasan dengan cara memanaskan logam agar terbentuk austenit kemudian dilakukan pendinginan cepat untuk mendapatkan struktur Martensit.

\section{Tempering}

Proses memanaskan kembali logam yang telah dikeraskan untuk menghilangkan tegangan dalam dan mengurangi kekerasan, pemanasan berkisar pada temperature $150-650{ }^{\circ} \mathrm{C}$ dan dinginkan secara perlahan lahan

Tempering dibagi menjadi Tempering temperatur rendah $\left(150-300{ }^{\circ} \mathrm{C}\right)$, Tempering temperatur menengah $\left(300-500{ }^{\circ} \mathrm{C}\right)$ dan Tempering temperatur tinggi $\left(500-650^{\circ} \mathrm{C}\right)$

\section{Waktu Tahan (Holding Time)}

Waktu yang diperlukan untuk mencapai temperatur pengerasan tergantung pada beberapa faktor seperti jenis tungku yang digunakan dan jenis elemen pemanasnya. Lama pemanasan pada temperatur pengerasan tergantung dari jenis material dan temperatur pemanas yang dipilih

Dalam banyak hal, umumnya dipilih temperatur pengerasan yang tertinggi dari rentang temperatur pengerasan yang telah ditentukan. Tetapi jika penampang penampang dari benda kerja yang diproses menunjukan adanya perbedaan yang besar, umumnya dipilih temperatur pengerasan terendah.

\section{Sifat Mekanik Material}

Gaya dari luar yang bekerja pada material akan berpengaruh terhadap kondisi fisik material tersebut atau dengan kata lain material akan mengalami deformasi.

Deformasi terhadap logam dibedakan sebagai berikut yaitu :

\section{Deformasi Elastis}


Deformasi ini bekerja sementara, karena bila gaya yang bekerja pada logam dihentikan maka kondisi fisik logam akan kembali keadaan semula.

\section{Deformasi Plastis}

Deformasi ini bersifat tetap, artinya walaupun gaya yang bekerja pada benda itu dihentikan, logam tidak akan kembali kekondisi semula.

Untuk mendapatkan sifat mekanik dari suatu material harus dilakukan pengujian yang pada dasarnya pengujian tersebut dibagi kedalam dua katagori yaitu :

\section{Pengujian Tidak Merusak (Non Destructive Test)}

Bahan yang diuji tetap utuh, antara lain
a. uji magnetic
b. uji penetran/tembus
c. uji ultra sonic
d. uji rontgen

2. Pengujian Merusak (Destructive Test)

Bahan yang diuji sengaja dirusak, antara lain
a. uji Tarik
b. uji kekerasan (hardness)
c. uji impact (pukul takik) atu benturan
d. uji laju keausan
e. uji kelelahan (fatique)
f. uji penjalaran (creep)
g. uji metallografi

\section{Pengujian Komposisi Kimia}

Uji komposisi kimia dilakukan untuk mengetahui kandungan unsur kimia paduan dalam logam. Pengujian dilakukan dengan menggunakan mesin Spectrometer. Data yang dihasilkan pada uji komposisi kimia menunjukan adanya beberapa unusr kimia. Dari hasil pengujian ini dapat dianalisa komposisi kimianya dan juga diketahui pengaruh dari masing-masing unsur kimia yang terkandung dalam material tersebut

\section{Kekerasan (Hardness)}

Kekerasan adalah suatu ukuran ketahanan material terhadap deformasi local/setempat

Ada beberapa metoda pengujian kekerasan yang dapat dilakukan antara lain :

Metoda Brinell (Brinell Hardness Test), metoda Vickers (Vickers Hardness Test) dan metoda Rockwell (Rockwell Hardness Test)

Untuk mencari nilai kekerasan dipakai metoda Vickers dan rumusnya adalah :

$$
V H N=\frac{2 P \cdot \sin \frac{136}{2}}{L^{2}} \quad \text { atau } \quad V H N=\frac{1,854 P}{L^{2}}
$$

$\mathrm{P}=$ beban penekanan $(1 \mathrm{~s} / \mathrm{d} 120 \mathrm{~kg})$

$\mathrm{L}=$ panjang diagonal rata-rata $(\mathrm{mm})$

$\Theta=$ sudut antara permukaan intan $136^{\circ}$

\section{Struktur Mikro}

Metalografi adalah ilmu yang mempelajari tentang pemeriksaan logam untuk mengetahui sifat, struktur, temperatur, dan persentase campuran dari logam tersebut.

Metode pada pengujian ini terdapat dua jenis pemeriksaan yaitu :

\section{Pemeriksaan \\ Examination) \\ Makro \\ (Macrocospic}

Pemeriksaan makro adalah pemeriksaan bahan dengan mata langsung atau menggunakan kaca pembesar dengan pembesaran rendah. Kegunaannya untuk memeriksa permukaan yang terdapat celah - celah, lubang - lubang pada struktur logam yang bersifat rapuh, bentuk bentuk patahan benda uji bekas pengujian mekanis yang selanjutnya dibandingkan dengan beberapa logam menurut bentuk dan strukturnya antara satu dengan yang lain menurut kebutuhannya.

\section{Pemeriksaan mikro (Microscopic Examination)}

Adalah pemeriksaan bahan logam dimana bentuk kristal logam tergolong halus sehingga diperlukan angka pembesaran lensa mikroskop antara 50x sampai 3000x atau lebih dengan menggunakan mikroskop industri.

\section{METODOLOGI PENELITIAN \\ Diagram Alir Penelitian}

Diagram alir penelitian dalam melakukan penelitian ini seperti terlihat pada gambar 2 dibawah ini :

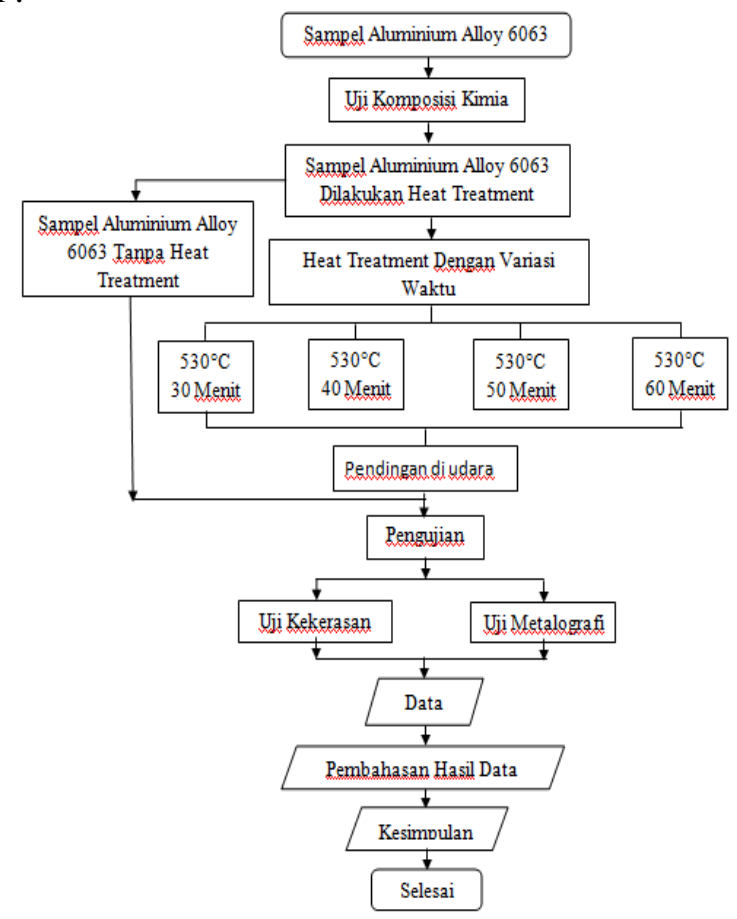

Gambar 2 Diagram Alir Penelitian

\section{Persiapan Benda Uji}


Benda uji yang digunakan untuk pengujian dalam penelitian ini adalah Aluminium Alloy tipe 6063 berbentuk tabung (silinder) yang kemudian dipotong menjadi 5 sample dengan diameter $50 \mathrm{~mm}$ dan tebal $10 \mathrm{~mm}$.

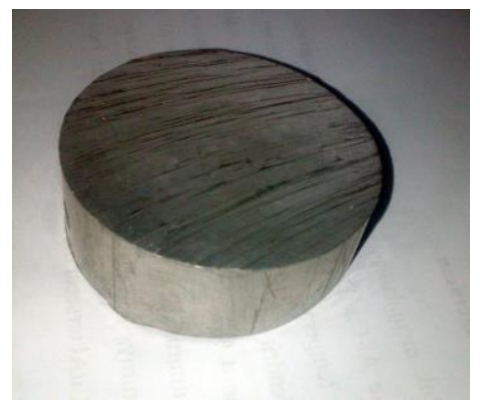

Gambar 3. Preparasi Sample

\section{Proses Perlakuan Panas (Heat Treatment)}

Proses ini dilakukan pada temperatur tetap (konstan) $530^{\circ} \mathrm{C}$ dengan variasi holding time mulai dari 30, 40, 50 dan 60 menit, kemudian di dinginkan dengan udara. Prosesnya sebagai berikut

1. Benda uji 1 dimasukan kedalam furnance heat tretment selama 30 menit dengan suhu pemanasan tetap $530{ }^{\circ} \mathrm{C}$ dan langsung dilakukan proses pendinginan dengan udara.

2. Benda uji 2 dimasukan kedalam furnance heat tretment selama 40 menit dengan suhu pemanasan tetap $530{ }^{\circ} \mathrm{C}$ dan langsung dilakukan proses pendinginan dengan udara.

3. Benda uji 3 dimasukan kedalam furnance heat tretment selama 50 menit dengan suhu pemanasan tetap $530{ }^{\circ} \mathrm{C}$ dan langsung dilakukan proses pendinginan dengan udara.

4. Benda uji 4 dimasukan ke dalam furnace heat ditahan sampai 60 menit dengan temparatur $530{ }^{\circ} \mathrm{C}$ dan langsung didinginkan dengan udara.

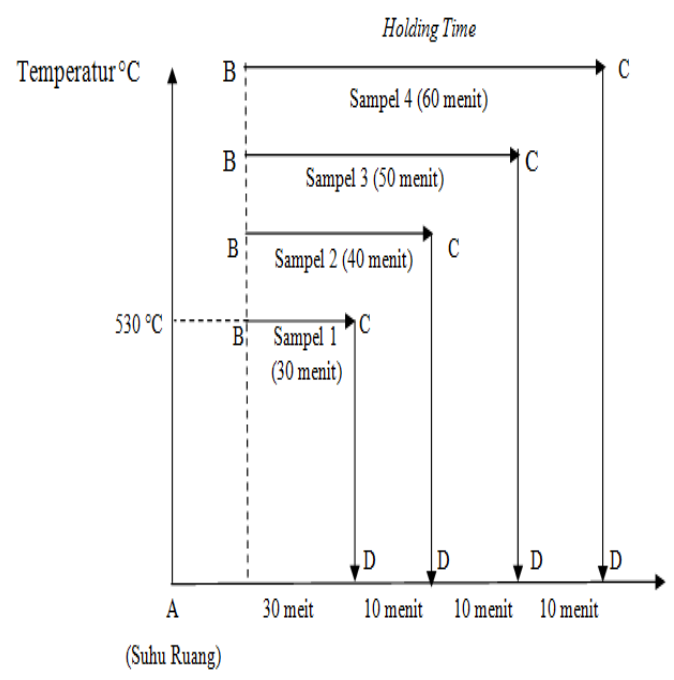

Gambar 4. Diagram Heat Treatment

$$
\begin{aligned}
& \mathrm{A}-\mathrm{B}=\text { Pemanasan } \\
& \mathrm{B}-\mathrm{C}=\text { Holding Time } \\
& \mathrm{C}-\mathrm{D}=\text { Pendinginan }
\end{aligned}
$$

\section{Tahapan Pengujian Pada Benda Uji \\ Pengujian Komposisi Kimia}

Pengujian komposis kimia dilakukan dengan menggunakan alat spectrometer yang urutan prosesnya sebagai berikut

1. Persiapan benda uji

Adapun persiapan benda uji yang dilakukan dengan, penghalusan permukaan, dan pemolesan

2. Pengujian

Pada pengujian komposisi kimia, bahan atau komponen dapat langsung segera dianalisa oleh alat Optical Emission Spectrometer (OES)

\section{Pengujian Kekerasan (Vickers)}

Nama alat uji yang digunakan untuk uji kekerasan Vickers adalah Frank Finotest dapat dilihat pada gambar 5

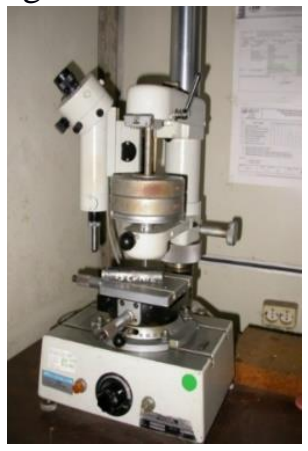

Gambar 5. Alat Uji Kekerasan (Vickers)

Data alat uji kekerasan Vickers:

Nama alat : Frank Finotest

Metode Uji : Hardness Vickers (HV)

Beban $(\mathrm{P}) \quad: 5 \mathrm{Kgf}$

Sudut Identor $: 136^{\circ}$

Waktu Uji : 15 detik

Temperatur Uji : $28^{\circ} \mathrm{C}$

Standar Uji : SNI 19-0409-1989

Langkah-langkah Pengujian Kekerasan

Menentukan benda uji, Memotong bahan yang akan diuji, Mengerinda / mengikir, Meratakan permukaan bahan uji yang telah dipotong, Mengamplas, Uji Kekerasan Vickers dengan benda uji valve (baja), Pengambilan data

\section{Pengujian Metalografi}

Tahapan dalam uji Metalografi, sebagai berikut, Pemotongan benda uji, Mounting, Pengamplasan (grinding), Polishising, Etsa, Proses pencucian dan terakhir Pengamatan dan pemotretan

Keterangan diagram heat treatment : 


\section{HASIL PENGUJIAN DAN PEMBAHASAN Komposisi Kimia}

Paduan aluminium tipe 6063 mempunyai komposisi kimia seperti yang ditunjukan pada tabel1. Terlihat bahwa paduan aluminium tipe 6063 mempunyai kandungan aluminium murni sebesar 98,7\% dan didominasi oleh magnesium dan silikon masing - masing sebesar $0,53 \%$ dan besi $0,23 \%$ serta terdapat beberapa unsur penunjang lainya seperti Mangan, Krom, Nikel, Tembaga, Vanadium, Titanium, Timbal, Seng, Niobium, dan Timah yang mempunyai kandungan tidak lebih dari $0,01 \%$.

Tabel 1. Komposisi Kimia Al 6063

\begin{tabular}{|c|c|c|c|}
\hline Code & No. & Unsure & R e s u l t (wt \% ) \\
\hline \multirow{7}{*}{} & 1 & $\mathrm{Al}$ & 98.7 \\
\cline { 2 - 4 } & 2 & $\mathrm{Fe}$ & 0.230 \\
\cline { 2 - 4 } & 3 & $\mathrm{Si}$ & 0.530 \\
\cline { 2 - 4 } 61-alloy & 4 & $\mathrm{Mn}$ & 0.0050 \\
\cline { 2 - 4 } & 5 & $\mathrm{Mg}$ & 0.532 \\
\cline { 2 - 4 } & 6 & $\mathrm{Cr}$ & 0.0010 \\
\cline { 2 - 4 } & 7 & $\mathrm{Ni}$ & 0.0050 \\
\cline { 2 - 4 } & 8 & $\mathrm{Cu}$ & 0.0064 \\
\cline { 2 - 4 } & 9 & $\mathrm{~V}$ & 0.0025 \\
\cline { 2 - 4 } & 10 & $\mathrm{Ti}$ & 0.0080 \\
\cline { 2 - 4 } & 11 & $\mathrm{Sn}$ & 0.0050 \\
\cline { 2 - 4 } & 12 & $\mathrm{~Pb}$ & 0.0050 \\
\cline { 2 - 4 } & 13 & $\mathrm{Nb}$ & 0.004 \\
\cline { 2 - 4 } & 14 & $\mathrm{Zn}$ & 0.0172 \\
\hline
\end{tabular}

Pengujian Kekerasan Vickers

Tabel 2. Nilai Kekerasan Al6063

\begin{tabular}{|c|c|c|c|c|c|}
\hline \multirow{2}{*}{ No. } & \multicolumn{5}{|c|}{ NILAI KEKERASAN, HV } \\
\cline { 2 - 6 } & $\begin{array}{c}\text { Sampel } \\
\text { Normal }\end{array}$ & $\begin{array}{c}\text { Samp } \\
\text { I } \\
\mathbf{3 0} \\
\text { menit }\end{array}$ & $\begin{array}{c}\text { Samp } \\
\text { II } \\
\mathbf{4 0} \\
\text { menit }\end{array}$ & $\begin{array}{c}\text { Samp } \\
\text { III } \\
\mathbf{5 0} \\
\text { menit }\end{array}$ & $\begin{array}{c}\text { Samp } \\
\text { IV } \\
\mathbf{6 0} \\
\text { menit }\end{array}$ \\
\hline 1 & 44.0 & 45.0 & 42.2 & 45.0 & 44.0 \\
\hline 2 & 47.7 & 42.5 & 38.6 & 44.6 & 45.8 \\
\hline 3 & 47.1 & 42.4 & 38.0 & 44.8 & 44.6 \\
\hline 4 & 46.2 & 43.1 & 38.0 & 44.0 & 44.6 \\
\hline 5 & 43.6 & 43.3 & 39.0 & 45.2 & 45.8 \\
\hline $\begin{array}{c}\text { Rata- } \\
\text { rata }\end{array}$ & 45,72 & 43,26 & 39,16 & 44,72 & 44,96 \\
\hline
\end{tabular}

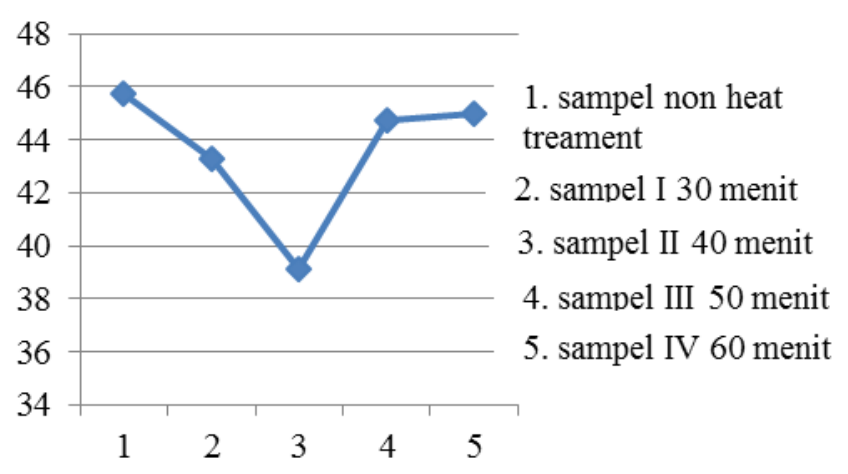

Gambar 6. Grafil Nilai rata - rata Uji Kekerasan

Gambar 6. merupakan nilai rata - rata uji kekerasan pada aluminium tipe 6063 yang telah dilakukan proses heat treatment pada temperatur tetap dengan variasi waktu tahan yang kemudian di dinginkan dengan udara. Nilai kekerasan yang paling tinggi terdapat pada sampel Aluminium non heat treatment dibandingkan dengan sampel Aluminium yang sudah di heat treatment tidak terjadinya kenaikan nilai kekerasan, hal ini diduga dari pemilihan temperatur pemanasan yang gunakan dalam penelitian tidak tepat.

\section{Hasil pengujian Metalografi}

\section{Hasil Struktur Mikro Sample Normal}

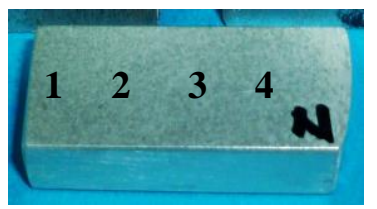

Gambar 7. Struktur Mikro Sampel Normal Lokasi 1,

$$
2,3 \text {, dan } 4
$$

Struktur mikro sampel kondisi normal tanpa perlakuan panas, pada lokasi 1 dan 2 didaerah tepi berupa phase alpha aluminium $(\alpha)$ presipitasi Si dan terbentuk besar butir, terlihat pada perbesaran 500x adanya penyebaran butir Si. Sedangkan pada lokasi 3 dan 4 terbentuk dendrite aluminium. Dengan nilai rata - rata kekerasan 45,72 HV. Etsa: dix's keller reagent.

\section{Hasil Struktur Mikro Sampel 1}

Pemeriksaan struktur mikro sampel 1 pada lokasi 1 dan 2, Pada daerah tepi terjadi pertumbuhan besar butir, sedangkan pada lokasi 3, 4 dan 5 terbentuk dendrite. Dengan nilai rata - rata kekerasan 43,26 HV. 

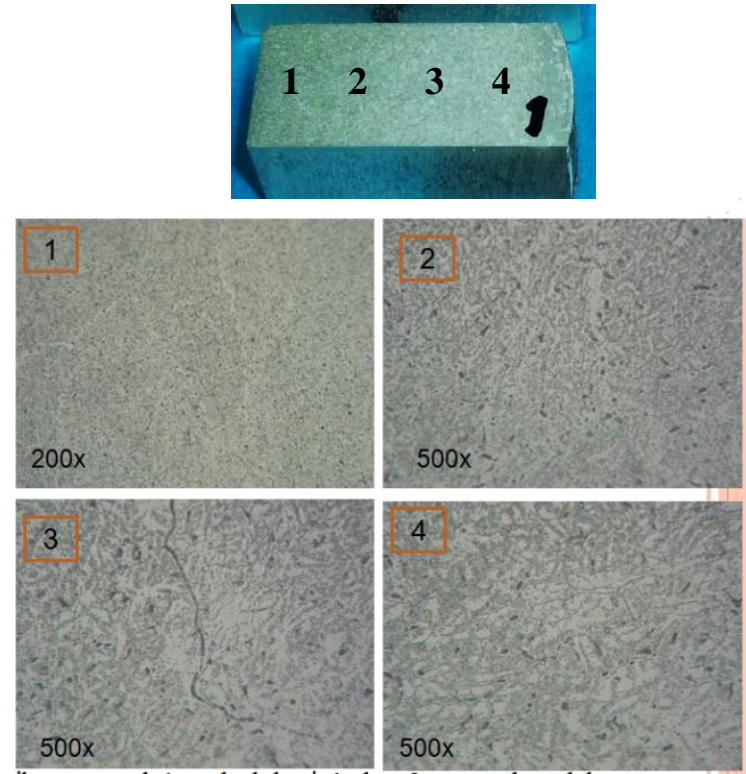

Gambar 8. Struktur Mikro Sampel Sample 1 Lokasi $1,2,3$, dan 4

\section{Hasil Struktur Mikro Sampel 2}
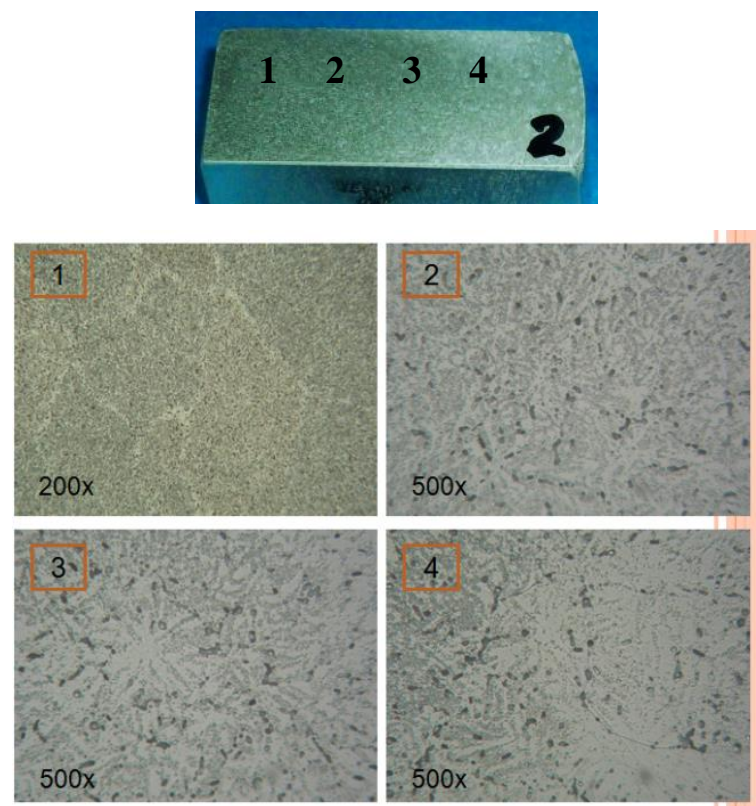

Gambar 9. Struktur Mikro Sampel 2

Lokasi 1, 2, 3 dan 4

Pemeriksaan struktur mikro sampel 2 pada lokasi 1 dan 2, Terjadi perubahan berupa pengelompokan butir halus dan adanya butir kasar aluminium, struktur mikro berupa phase alpha aluminium dan presipitasi Si pada batas butir, sedangkan pada lokasi 3 dan 4 terjadi pertumbuhan besar butir. Dengan nilai rata - rata kekerasan 39,16 $\mathrm{HV}$.

\section{Hasil Struktur Mikro Sampel 3}
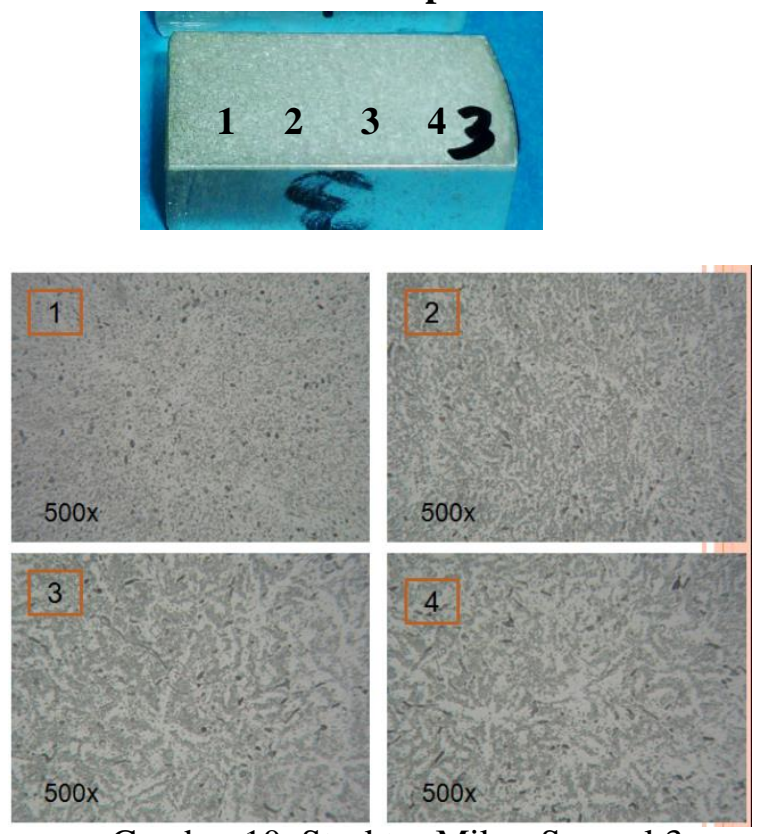

Gambar 10. Struktur Mikro Sampel 3
Lokasi 1, 2, 3 dan 4

Pemeriksaan struktur mikro sampel 3 pada lokasi 1 dan 2, Terjadi perubahan berupa pengelompokan butir halus dan adanya butir kasar aluminium, struktur mikro berupa phase alpha aluminium dan presipitasi Si pada batas butir, sedangkan pada lokasi 3 dan 4 berbentuk dendrite aluminium. Dengan nilai rata - rata kekerasan 44,72 HV.

\section{Hasil Struktur Mikro Sampel 4}
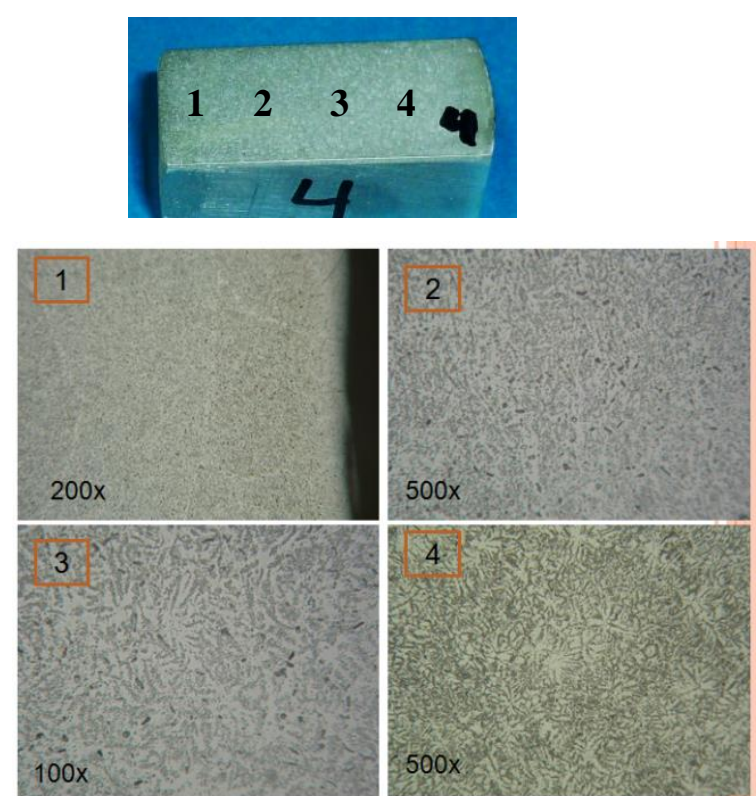

Gambar 11. Struktur Mikro Sampel 4 Lokasi 1, 2, 3 dan 4

Pemeriksaan struktur mikro sampel 4 pada lokasi 1, 2, 3 dan 4. Terjadi pertumbuhan besar butir dan terdapat dendrite aluminium. Dengan nilai rata rata kekerasan 44,96 HV. 


\section{SIMPULAN}

1. Hasil uji komposisi kimia dari material Aluminium 6063 mempunyai hasil kandungan Aluminium (Al) 98,7\%, Besi (Fe) 0,230\%, Silikon (Si) $0.530 \%$, Magnesium (Mg) $0.532 \%$. dari hasil tersebut dapat disimpulkan bahwa material aluminium 6063 adalah paduan Al$\mathrm{Mg}-\mathrm{Si}$.

2. Dari hasil pengamatan struktur mikro aluminium 6063 yang telah diberi perlakuan panas dengan temperature tetap $530^{\circ} \mathrm{C}$ dengan waktu tahan (holding time) yang bervariasi mulai dari 30, 40, 50 dan 60 menit dengan media pendinginan udara terdapat struktur dendrite Alumunium dan penyebaran butir Silikon serta terbentuknya pembesaran butiran

3. Hasil pengujian kekerasan material Aluminium 6063 yang tanpa di heat treatment maupun yang dilakukan heat treatment menghasilkan nilai kekerasan hamper sama, rata rata sebesar 44,66 HV kecuali untuk waktu tahan selama 40 menit nilai kekerasannya turun sebesar 39,16 $\mathrm{HV}$

4. Uji kekerasan dengan temperature tetap sebesar $530{ }^{\circ} \mathrm{C}$ dan variasi waktu 30 menit, 40 menit, 50 menit, 60 menit tidak menimbul hasil yang signifikan, sehingga dengan pemanasan ini tidak terjadi kenaikan nilai kekerasan.

5. Kemungkinan tidak terjadinya kenaikan kekerasan akibat variasi waktu tahan dengan temperatur tetap diakibatkan temperatur pemanasan yang kurang.

\section{DAFTAR PUSTAKA}

Hatch, J.E, Aluminium : Properties and Physical Metallurgy, American Society for Metals, 1984.

Sriati Djaprie, Metalurgi Mekanik, PT. Erlangga, Jakarta, 1993.

Adyana D.N, Metalurgy For The NonMetalurgist, Puncak Sari, Belawan Sumut, 2003.

Adyana D.N, Teknologi Manufaktur Logam Industri, ISTN, Jakarta, 2014.

Van Viet, G.L.J, Teknologi untuk Bangunan Mesin Bahan - bahan, PT. Erlangga, Jakarta, 1984.

Rohmat, Rudianto. "Heat Treatment Pada Aluminium Paduan". 24 Oktober 2010. https://matrudian.wordpress.com/2010/10/2 4/heat-treatment-pada-aluminium-paduan/

Bangkit, Shanjaya. "Macam - macam Aluminium Paduan". $13 \quad$ November 2013. http://maknewsnews.blogspot.co.id/2013/11
Imacam-alloy-alluminium-danpaduannya.html?m=1

Adi, yeuwono. "Perlakuan Panas Pada Logam Dan Jenisnya". 04 juni 2011. http://teknosehat.blogspot.co.id/2011/06/Perlakuan-

Panas-(Heat Treatment)-Pada-Logam-DanJenisnya/

http://id.wikipedia .org/wiki/Aluminium www.google.com 